\title{
Drywood Termite, Cryptotermes cavifrons Banks (Insecta: Isoptera: Kalotermitidae) ${ }^{1}$
}

Angela S. Brammer and Rudolf H. Scheffrahn ${ }^{2}$

\section{Introduction}

Termites of the genus Cryptotermes were sometimes called powderpost termites because of the telltale heaps of fecal pellets (frass) that accumulate beneath infested wood. Fecal pellets of Cryptotermes, however, are similar in size and shape to other comparably sized species of Kalotermitidae. All are now collectively known as drywood termites. The most economically significant termite in this genus, Cryptotermes brevis (Walker), commonly infests structures and was at one time known as the "furniture termite," thanks to the frequency with which colonies were found in pieces of furniture. A member of the same genus that might be mistaken for $C$. brevis upon a first, cursory examination is $C$. cavifrons, a species endemic to Florida.

\section{Distribution and History}

Cryptotermes cavifrons has an unusually broad distribution for a Cryptotermes species. It ranges from the Florida peninsula to the Cayman Islands, Cuba, the Bahamas, Jamaica, and Turks and Caicos islands. Records from Puerto Rico, St. Croix, Haiti and Central America are erroneous.
Cryptotermes cavifrons is endemic to all of peninsular Florida, from St. Johns County south, unlike $C$. brevis, which is suspected to have been introduced through the Florida Keys in the early 1900s. Cryptotermes cavifrons is common in dry, dead trees, logs, stumps and branches, but it is rarely found infesting structures, due to higher moisture requirements than those of $C$. brevis. A 2002 termite survey of state parks in central and southern Florida found that 45 percent (187 of 416) of all kalotermitid samples taken were $C$. cavifrons.

\section{Identification}

Because termite workers are indistinguishable from each other to the level of species, most termite keys rely on characteristics of soldiers and alates (winged, unmated reproductives) for species identification.

Like all kalotermitids, the pronotum of the $C$. cavifrons soldier is about as wide as the head. The head features a large cavity in front (hence the species name, cavifrons), nearly circular in outline from an anterior view, shaped almost like a bowl. The rest of the upper surface of the head is smooth, as

1. This document is EENY-279, one of a series of Featured Creatures from the Entomology and Nematology Department, Florida Cooperative Extension Service, Institute of Food and Agricultural Sciences, University of Florida. Published: December 2002. This document is also available on Featured Creatures Website at http://creatures.ifas.ufl.edu. Please visit the EDIS Website at http://edis.ifas.ufl.edu. Additional information on these organisms, including many color photographs, is available at the Entomology and Nematology Department website at http://entnemdept.ifas.ufl.edu/. 2. Angela S. Brammer and Rudolf H. Scheffrahn, Entomology and Nematology Department, AREC, University of Florida, Ft. Lauderdale, FL.

The Institute of Food and Agricultural Sciences (IFAS) is an Equal Employment Opportunity - Affirmative Action Employer authorized to provide research, educational information and other services only to individuals and institutions that function without regard to race, creed, color, religion, age, disability, sex, sexual orientation, marital status, national origin, political opinions or affiliations. For information on obtaining other extension publications, contact your county Cooperative Extension Service office. Florida Cooperative Extension Service / Institute of Food and Agricultural Sciences / University of Florida / Larry R. Arrington, Interim Dean 
contrasted with the head of $C$. brevis, which has a similar cavity, but a rough and bumpy dorsal surface. The soldiers use their heavily sclerotized, plug-shaped heads (a condition known as phragmosis) to block entrance and exit holes to the nest. This is their primary mode of defense. Soldiers are 3.5 to $5.0 \mathrm{~mm}$ long. Their head capsules are black at the front and gradually more reddish toward the back. The rest of the body is brownish yellow with pale yellow legs and nearly white antennae. Unfortunately for those wishing to identify $C$. cavifrons by its soldiers, it may be difficult to obtain a sample as soldiers make up only 1 to 2 percent of a colony.

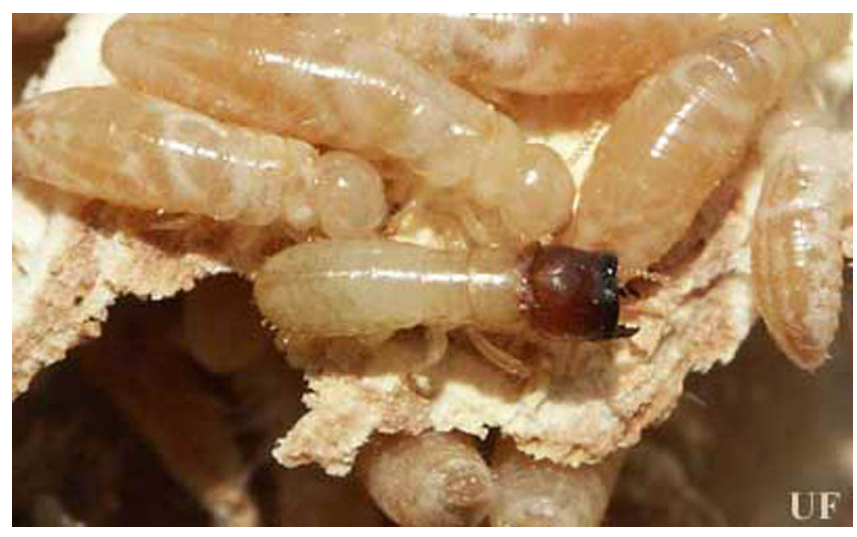

Figure 1. A Cryptotermes cavifrons soldier, recognizable by its sclerotized and darkened head, is surrounded by workers. Soldiers make up only 1-2 percent of the typical Cryptotermes cavifrons colony. Credits: Rudolf $\mathrm{H}$.

Scheffrahn, University of Florida

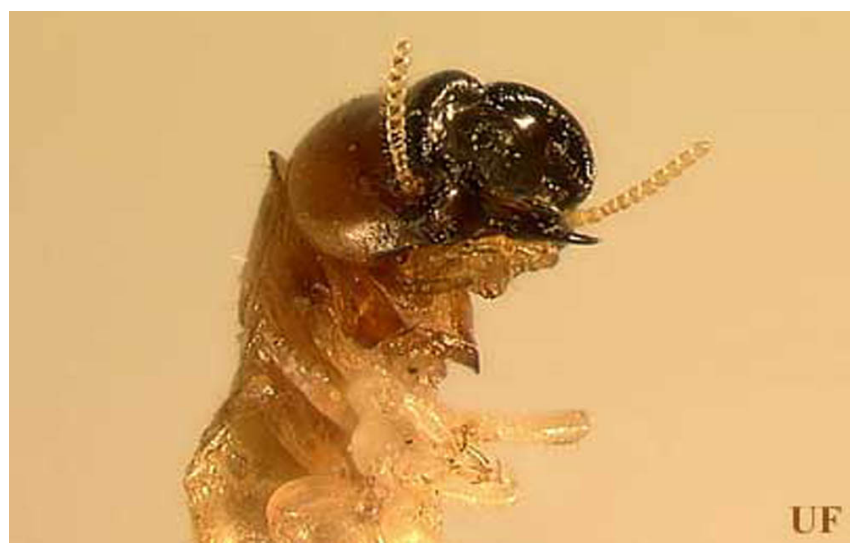

Figure 2. A close-up view of a Cryptotermes cavifrons soldier's head shows the pluglike, or phragmotic, head that is characteristic of the genus. The dorsal, posterior surface of the head is smooth, characteristic of the species.

Credits: Angela S. Brammer, University of Florida

Alates are approximately 8.5 to $9.7 \mathrm{~mm}$ long, including wings. The head and body are dull, pale brown. The width of the head is less than $1 \mathrm{~mm}$, and the antennae are much longer than the head, with 10 to 14 (usually 11 or 12) segments. The wings have three to four sclerotized (hardened and thickened) veins visible in the third of the wing closest to the body. The forewings also have an unsclerotized median vein that curves upward to the sclerotized veins about midwing. The wings are long, with the tip of the abdomen often reaching only about halfway down the length of the wing. The wing scale (the darkened base of the wing where it attaches to the body) is often about the same length as the pronotum.

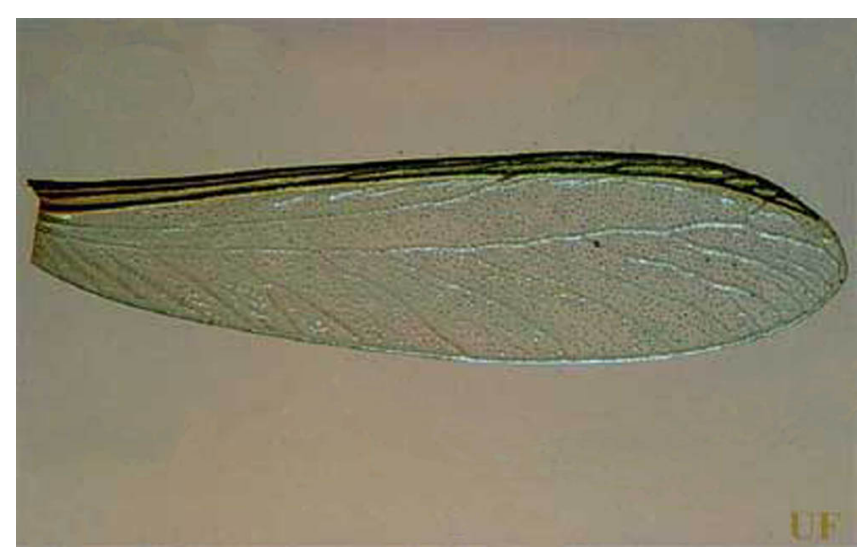

Figure 3. Close-up of a Cryptotermes cavifrons wing. Three heavily sclerotized veins are distinctly visible in the basal third of the wing. The unsclerotized median vein curves upward to meet the sclerotized veins about midwing. Credits: Rudolf H. Scheffrahn, University of Florida

\section{Life Cycle and Biology}

Drywood termites, like all termites, are eusocial insects. They live in colonies and cooperatively care for young. Responsibilities for reproduction, foraging and colony defense are divided up among castes: reproductives (king, queen and alates), workers and soldiers. In drywood termites, the "worker" caste does not consist of true workers that are reproductively sterile and found in the higher termites of the family Termitidae. Rather, immature termites do the labor of the traditional worker caste, and they are known as pseudergates ("false workers"). All the castes have chewing mouthparts, although the mandibles of the soldiers are greatly modified for defense to the point that they must be fed by the pseudergates. All but the reproductives are blind.

As with other drywood termites, $C$. cavifrons gradually constructs a maze of meandering 


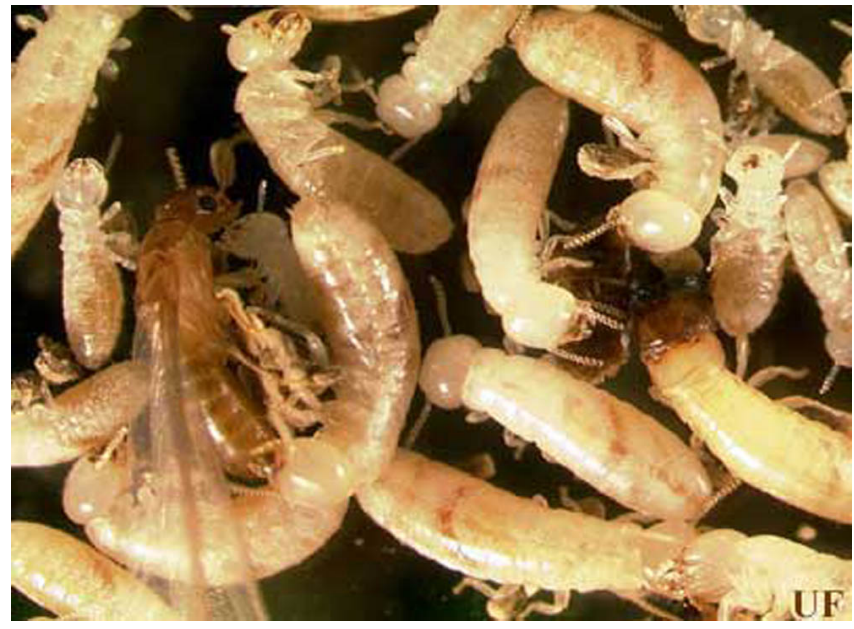

Figure 4. Larvae and pseudergates ("false workers") surround a winged reproductive (alate), left, and soldier, right. Soldiers make up only 1-2 percent of the typical Cryptotermes cavifrons colony. Credits: Angela S. Brammer, University of Florida

interconnected galleries. The brood (eggs, larvae and young pseudergates) are found in some of them - an indication that the king and queen are nearby.

After the eggs hatch into larvae and go through about three molts, the young begin the process of separating into castes. Some molt into presoldiers, which resemble soldiers in form but are unsclerotized and thus white in color. Others become nymphs, which will eventually develop into winged reproductives, or alates. Other larvae molt to become the worker class of the colony, taking care of excavating galleries keeping the soldiers fed. Drywood termite pseudergates are different from subterranean termite workers in that they can continue to develop into alates should a need arise in the colony. In the family Termitidae, workers are sterile adults, and the path to that caste is a one-way street. Once a worker, always a worker.

Eventually, nymphs molt into alates. Swarms occur when these alates leave the colony to start new colonies elsewhere. Cryptotermes cavifrons is an unusual species in that alates are present in colonies throughout the year. Swarms occur in the evenings all year long, but the peak swarming time is March through May. Termites are weak fliers and tend to flutter about on the wind as much as actively fly. It is likely that they will not stray too far from the original colony in their dispersal flights.

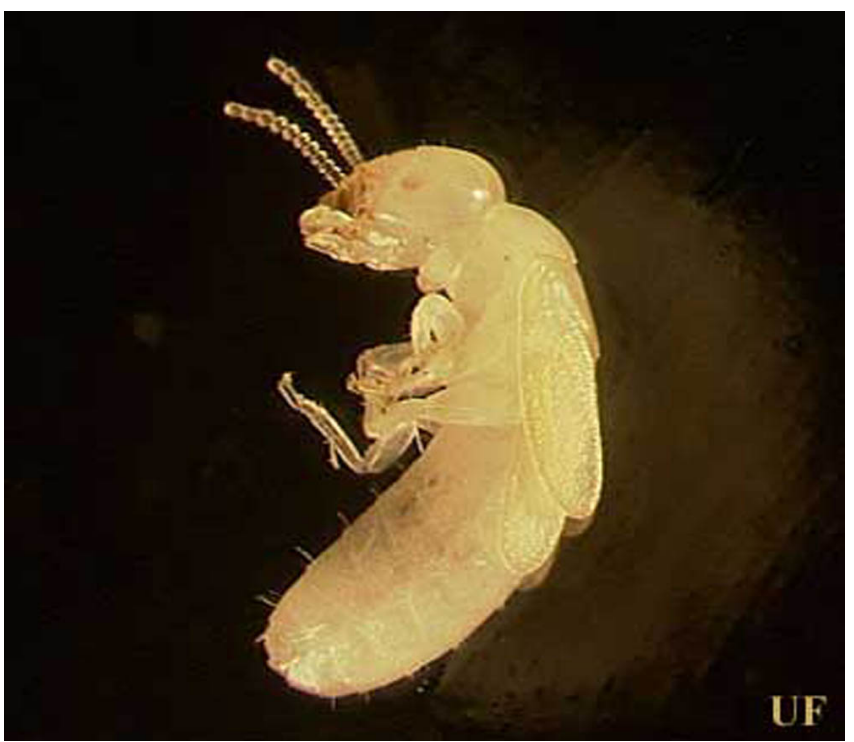

Figure 5. The presence of wing pads indicates that this Cryptotermes cavifrons individual is a nymph. Eventually it will develop into an alate, or swarmer, with wings and reproductive capabilities. Credits: Angela S. Brammer, University of Florida

When alates land, they twist off their wings, find a mate and burrow into a suitable location in the wood such as a knothole or crevice and mate. Alates who have broken off their wings are called dealates. Eggs then take several months to hatch.

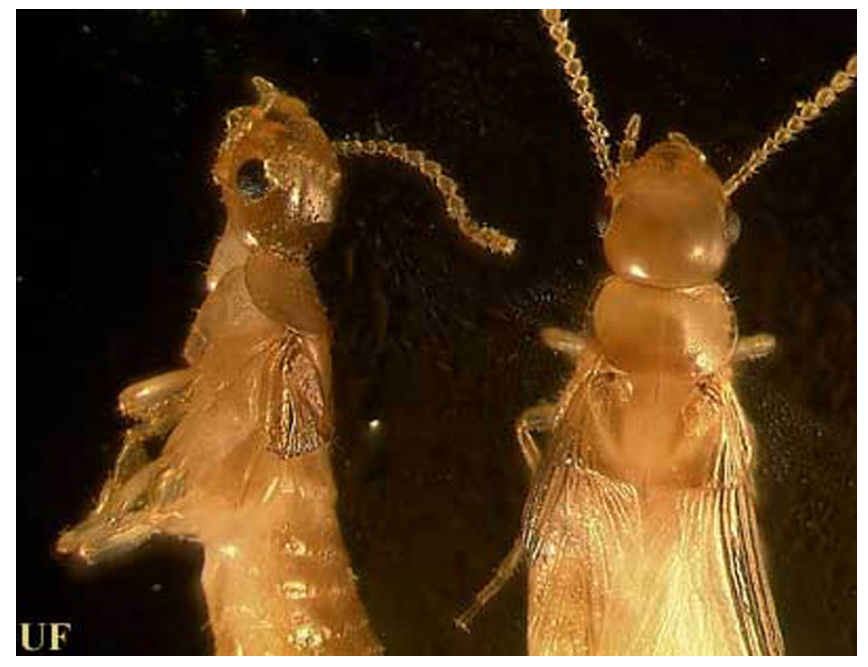

Figure 6. The Cryptotermes cavifrons dealate on the left has already broken off its wings. Note that the scales where the wings attached to the body remain in place. They are about the same length as the pronotum. Credits: Angela S. Brammer, University of Florida

Drywood termite colonies develop slowly. The entire colony may take five years or more to mature. Limited space and resources prevent them from even attempting the rapid growth of subterranean colonies. 
Even with optimal resources, the growth rate of drywood colonies is slow due to their low inherent reproductive rate. Drywood termites' legs are actually shorter than subterranean termites' legs, as well, and they literally move slower as a result. Also, in their preferred habitat, water is a precious resource in limited supply at certain times of the year. Drywood termites have several adaptations for conserving as much water as possible. Three pairs of rectal glands compress their feces to remove and retain all water possible before waste excretion. This results in hexagonal fecal pellets (frass). These six-sided pellets, usually found in small piles, are indicative of drywood termite infestation. In $C$. cavifrons termites, the pellets are small and feel like grains of coarse sand when rubbed between the fingers. Drywood termites depend heavily on production of metabolic water.

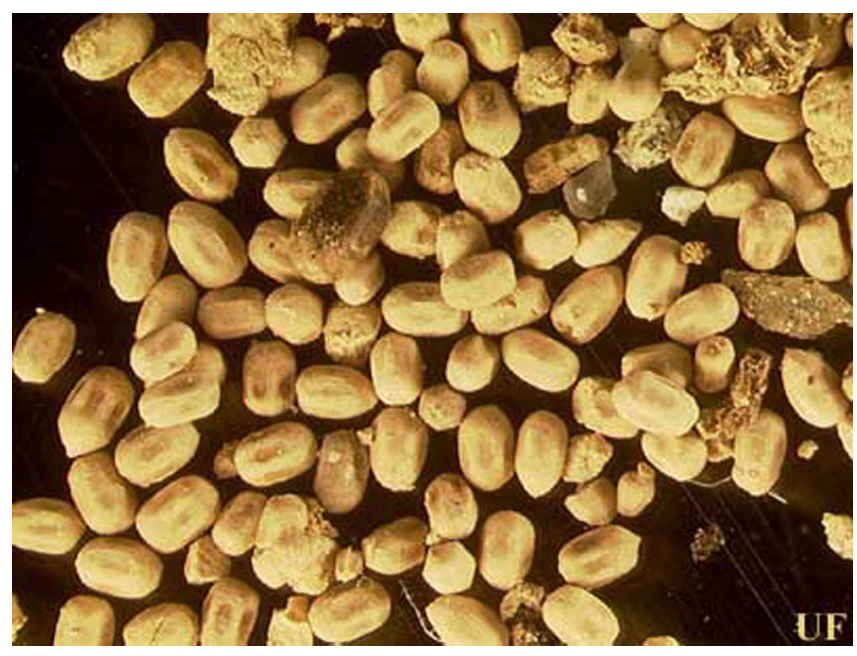

Figure 7. Cryptotermes cavifrons' three pairs of anal glands extract every last bit of water possible before waste excretion, producing the hexagonal fecal pellets seen here. For scale, the glassy "rock" near the top right of the photo is a grain of sand. Credits: Angela S. Brammer, University of Florida

Galleries cross the grain in wood, but the colony remains confined to that wood with only alates emerging during flights. No contact with the ground is necessary for a Cryptotermes cavifrons colony to become established.

\section{Damage}

External signs of damage are elusive with drywood termites. Often, the only obvious signs of infestation are little mounds of fecal pellets building up underneath the infested wood or the appearance of "kick-out" holes in the surface of the wood. Drywood termites make tiny holes in the surface of the wood that allow them to expel their fecal pellets.

Cryptotermes cavifrons soldiers can quickly plug the holes with their phragmotic heads if necessary. Some holes also may be closed off with a temporary paperlike substance. These holes are usually very difficult to see because they are very small (about 1 $\mathrm{mm}$ ) and seldom open. The diameter of the frass piles is proportional to the height of the kick-out holes. Homeowners frequently mistake frass piles for sawdust.

\section{Management}

Drywood termite infestations are difficult to deal with. Most of the time, infestations are localized, as colonies live entirely with a particular piece of sound, dry wood. But sometimes the infestation is not noticed until the colony has matured and produced alates that have already begun new, undetectable colonies in wood nearby. Localized treatment of the first colony then does nothing about the second or third that may already be developing. Treatments are divided into several types: whole structure; compartmental, such as an attic; and local, such as a windowsill. They range from fumigation and excessive temperature to wood injections and localized electrocution. Each method has its own pros and cons. Preventative treatments are generally made only when there has been a prior treatment for an infestation. To learn more about drywood termite management, please see Drywood Termite Control: Weighing All the Options.

Fortunately, although it is very common in natural settings, $C$. cavifrons only rarely infests homes or buildings. Only a few instances have been reported of $C$. cavifrons in structures.

\section{Selected References}

Banks N, Snyder TE. 1920. A revision of the nearctic termites with notes on biology and distribution. U.S. Government Printing Office, Washington, DC. 
Craighead FC. 1950. Insect enemies of eastern forests. U.S. Government Printing Office, Washington, DC.

Edwards R, Mill AE. 1986. Termites in buildings: their biology and control. Rentokil Ltd., East Grinstead, U.K.

Harris WV. 1971. Termites: Their Recognition and Control. Longman Group Ltd., London.

Howse PE. 1970. Termites: A Study in Social Behaviour. Hutchinson \& Co. Ltd., London.

Morton ME. 1949. A Handbook on Florida Termites. University of Miami Press, Coral Gables, Fla.

Scheffrahn RH, Krecek J. 1999. Termites of the genus Cryptotermes Banks (Isoptera: Kalotermitidae) from the West Indies. Insecta Mundi 13: 111-170.

Scheffrahn RH, Su N-Y. (1997). Drywood termite control: weighing all the options. Ft. Lauderdale REC Research Report 97-1. http://flrec.ifas.ufl.edu/entomo/ Structural_Entomology/drywood/drywood.htm (7 August 2002).

Scheffrahn RH, Su N-Y. 1996. Key to termite soldiers of Florida. Ft. Lauderdale REC Research Report 96-2.

Scheffrahn RH, Su N-Y. 1996. Key to winged termites of Florida. Ft. Lauderdale REC Research Report 96-3.

Scheffrahn RH, Su N-Y. (April 1999). West Indian powderpost drywood termite, Cryptotermes brevis (Walker). UF/IFAS Featured Creatures. http://creatures.ifas.ufl.edu/urban/termites/ west_indian_drywood_termite.htm (7 August 2002).

Snyder TE. 1948. Our Enemy the Termite. Comstock Publishing Co., Inc., Ithaca, New York.

Snyder TE. 1954. Order Isoptera: The Termites of the U.S. and Canada. National Pest Control Association, Dunn Loring, VA. 